\title{
Trigeminal neuropathy with nasal ulceration: report of two cases and one necropsy
}

\author{
J. D. SPILLANE AND H. URICH \\ From the Department of Neurology, University Hospital of Wales, Cardiff, \\ and the Institute of Pathology, The London Hospital, London
}

SYNOPSIS Two cases are reported of progressive trigeminal neuropathy with nasal ulceration. One patient developed signs of spinal cord involvement 15 years after the onset of trigeminal symptoms and died after a total course of 21 years. Necropsy revealed an unusual trigeminospinal system degeneration with deposition of amyloid-like substances in the affected structures. The other patient is alive eight years after the onset of symptoms, the only indication of a lesion outside the trigeminal nerve being a patch of numbness in one leg.

In a previous paper on isolated trigeminal neuropathy (Spillane and Wells, 1959) one of us described a patient with total bilateral trigeminal loss accompanied by progressive ulceration of her nose (case 15). We now wish to report the subsequent evolution of her condition and postmortem findings which we believe to be unique. We also wish to record another patient who displayed similar symptoms and signs, at least in the early stages of her disease.

\section{CASE 1}

CLINICAL HISTORY A widow, aged 59 years, was first seen in 1950. Her illness began in 1949 with redness and pain of both eyes. She attended an ophthalmic clinic where a diagnosis of bilateral keratoconjunctivitis (Sjögren's disease) was made. A few months later a red, tender, and painful sore appeared at the edge of her left nostril. Biopsy in 1950 showed a hyperkeratotic lesion with superficial inflammation but no evidence of neoplasm. The sore increased in size and the outer margin of the nostril was progressively eroded. In January 1951 both sides of her forehead became numb; six months later her left upper lip was numb. Thereafter, numbness spread rapidly over the whole of the left side of her face and in August 1951 over the right side of her face. Her mouth and tongue became dry. In October 1951 there was bilateral keratoconjunctivitis with small irregular pupils and bilateral corneal opacities. Her left nostril was ulcerated (Fig. 1a and b). The corneal (Accepted 19 August 1975.) reflexes were absent and the sensations of touch, pain, and temperature were impaired in the first and second divisions on both sides, loss being absolute for all modalities on the left side. There were slighter changes in both third divisions. Deep pressure and vibration sense were normal. Taste was absent in the anterior two-thirds of the tongue. She could not appreciate the temperature of food on the left side

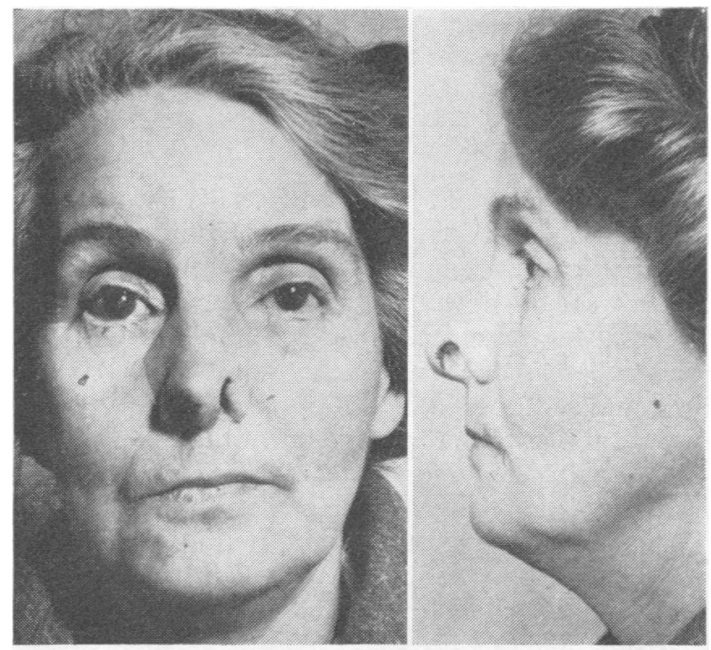

(a)

(b)

FIG. 1 Case 1. Two years after onset; erosion of left ala nasi, bilateral ptosis, and neuropathic keratitis. 
of her mouth. There was no involvement of the motor root of either trigeminal nerve. There was no symptom or sign of involvement elsewhere in the nervous system and investigations were entirely negative. No evidence of syphilis, sarcoidosis, systemic lupus, or scleroderma emerged.

Over the years her condition steadily worsened. By 1957 her nose was totally eroded (Fig. 2a and b), she was profoundly anaemic and she lost much weight. Eyesight was grossly impaired because of corneal opacities, she chewed and swallowed with

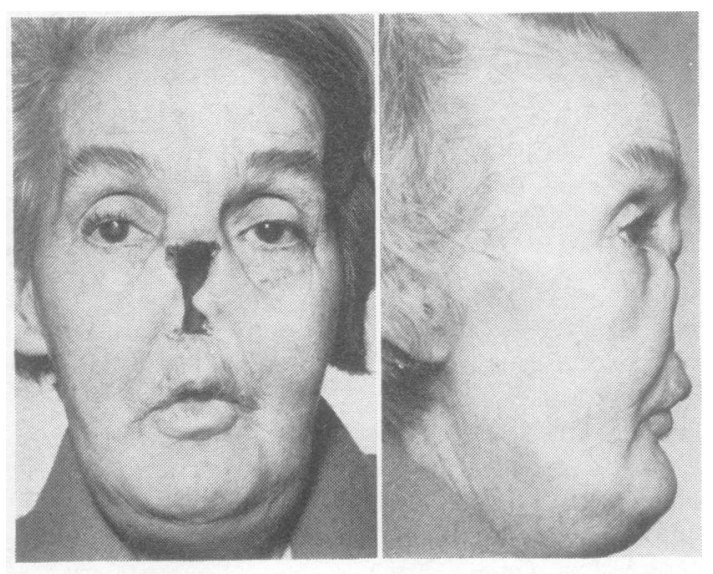

(a)

(b)

FIG. 2 Case 1. Six years later; total destruction of nose, bilateral trigeminal anaesthesia.

difficulty, and had no sense of taste. Nevertheless, she remained alert and uncomplaining; repeated neurological examinations were otherwise negative. There was still no sign of involvement of the motor roots of the trigeminal nerves but the sensory loss had progressed. She could scarcely detect the presence of food in her mouth. Sensory loss was more or less complete in both first and second divisions of the trigeminal nerves; it was impaired in both third divisions. Deep sensation was impaired. There was bilateral ptosis, small pupils, and loss of secretions from lacrimal and salivary glands. She retained a very feeble sense of smell.

From 1958 onwards, until her death in 1970 from bronchopneumonia at the age of 78 years, she refused hospital admission and neurological examinations had to be made in her home. In the 1960s she became very thin, her jaw movements were weak and no contraction of masticatory muscles could be palpated. There was almost total bilateral trigeminal anaesthesia. Hearing remained normal, speech intelligible. By the mid-'60s she was becoming unsteady on her feet and she often stumbled and fell. Sphincter functions were not affected. She complained that her legs were cold and she often wrapped them in a shawl and retired to bed. The lower limbs were very thin but arterial pulsations at the ankles were normal. Knee and ankle jerks were gradually reduced and subsequently lost. Extensor plantar reflexes were first detected in 1965 and remained until her death five years later. No sensory abnormality was found in her lower limbs until 1966 when posture and vibration could not be appreciated in her feet. Subsequently, vibration could not be appreciated below the knees. Superficial sensation was impaired only distally and never profoundly. In her upper limbs, superficial sensation did not seem to be impaired, although grips were weak and hands clumsy. There was postural and vibration loss in the hands; the arm reflexes were never lost. She remained able to feed herself with difficulty until her terminat? illness. She was alert and orientated until the end.

Thus, this strange neurological illness began in the trigeminal sensory system and some 15 years late巾 involved the spinal cord. There were no clues to if nature.

NECROPSY FINDINGS (West Cardiff Area Laborator P.M. 213/70) There were no significant abnormale ties outside the nervous system. In particular there was no evidence of generalized amyloidosis, multiple myeloma, systemic lupus erythematosus, or any other multisystemic disease.

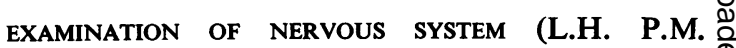
4/A/71) The macroscopic appearances of the brain were unremarkable. Transverse sections through the spinal cord showed symmetrical greyish discoloration in the posterior parts of the lateral columns and $\supset$ in the posterior columns, particularly the fasciculus? gracilis.

MICROSCOPIC APPEARANCES The lesions were confined to the trigeminal nerve and its pathways, and to the long tracts of the spinal cord.

SENSORY ROOT OF TRIGEMINAL NERVE The entire 0 root from its entry into the pons to the proximity of the Gasserian ganglion was severely affected. The glial part of the root was devoid of axons and myelin sheaths and showed astrocytic proliferation with $\tilde{N}$ fibrillary gliosis. Distal to the glio-SchwannianN junction, the root was infiltrated by an abnormalN substance, consisting of two components, $\mathrm{A}$ and $\mathrm{B}$, 
TABLE

STAINING REACTIONS OF INFILTRATING SUBSTANCES

\begin{tabular}{|c|c|c|c|}
\hline \multirow[t]{2}{*}{ Method } & \multicolumn{2}{|c|}{ Substance } & \multirow{2}{*}{$\begin{array}{c}\text { Control } \\
\text { (sporadic amyloid neuropathy) }\end{array}$} \\
\hline & $A$ & $\boldsymbol{B}$ & \\
\hline Congo red + polarized light & $\begin{array}{l}\text { Weakly positive birefringent, } \\
\text { dichroic, polarization colour } \\
\text { green }\end{array}$ & Negative & $\begin{array}{l}\text { Strongly to weakly positive } \\
\text { birefringent, dichroic, } \\
\text { polarization colour green }\end{array}$ \\
\hline Sirius red + polarized light & $\begin{array}{l}\text { Positive birefringent, dichroic, } \\
\text { polarization colour green }\end{array}$ & Negative & $\begin{array}{l}\text { Positive birefringent, dichroic } \\
\text { polarization colour green }\end{array}$ \\
\hline $\begin{array}{l}\text { Wolman's toluidine blue }+ \text { polarized } \\
\text { light }\end{array}$ & $\begin{array}{l}\text { Purplish blue birefringent, } \\
\text { dichroic, polarization colour } \\
\text { red }\end{array}$ & Blue & $\begin{array}{l}\text { Purplish blue birefringent, } \\
\text { dichroic, polarization colour } \\
\text { red }\end{array}$ \\
\hline Crystal violet & Gamma metachromasia (red) & $\begin{array}{l}\text { Beta metachromasia } \\
\text { (purple) }\end{array}$ & Gamma metachromasia (red) \\
\hline $\begin{array}{l}\text { Lendrum's sodium sulphate-alcian } \\
\text { blue-van Gieson }\end{array}$ & Green & Khaki & Green \\
\hline Thioflavin $\mathrm{T}$ & Greenish fluorescence & Greenish fluorescence & Greenish fluorescence \\
\hline Luxol-fast blue-cresyl violet & Light blue & Dark blue & Light blue \\
\hline
\end{tabular}

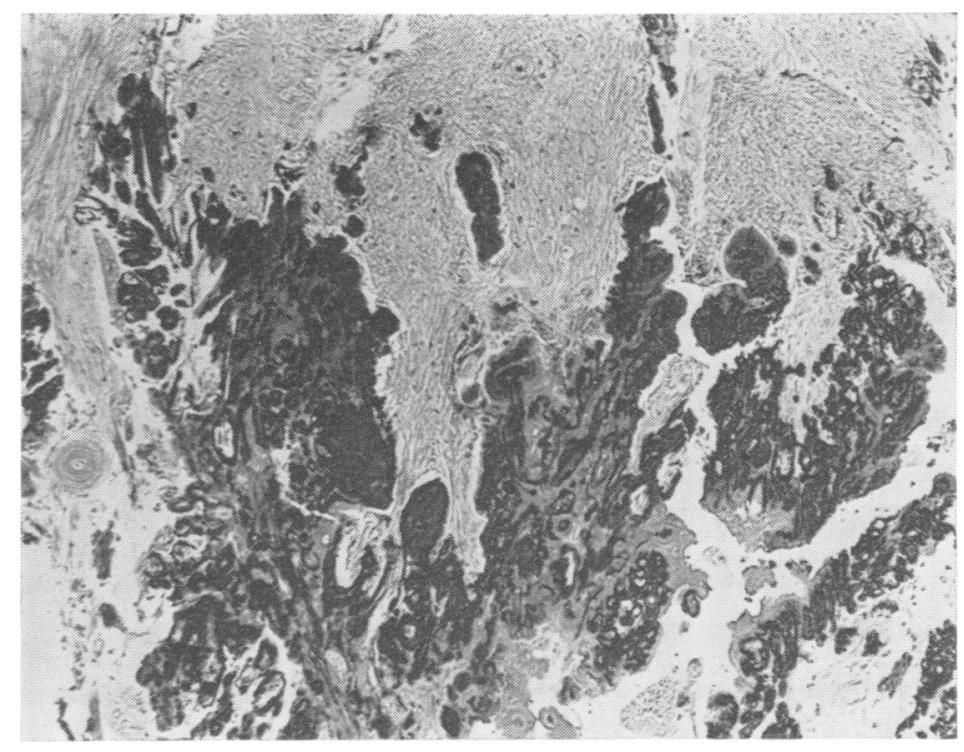

FIG. 3 Case 1. Trigeminal root; infiltration of glio-Schwannian junction by amyloid-like material. Lighter component represents substance $A$, darker substance $B$. Crystal violet, $\times 90$.

with different staining reactions (Table). Substance A was abundant at the junction, gradually giving way to infiltration with substance B (Fig. 3). Throughout its length, the root was devoid of axons and myelin sheaths, the individual fibres being infiltrated with substance B. This formed solid or tubular strands varying in thickness, with a somewhat irregular outline and a tendency to coarse beading in places (Fig. 4). The infiltration stopped short of the entry of the sensory root into the trigeminal ganglion where some deposits of substance A again became apparent. Throughout the length of the root the walls of blood vessels were infiltrated with substance $B$.

GASSERIAN GANGLION The neurones of the trig- 


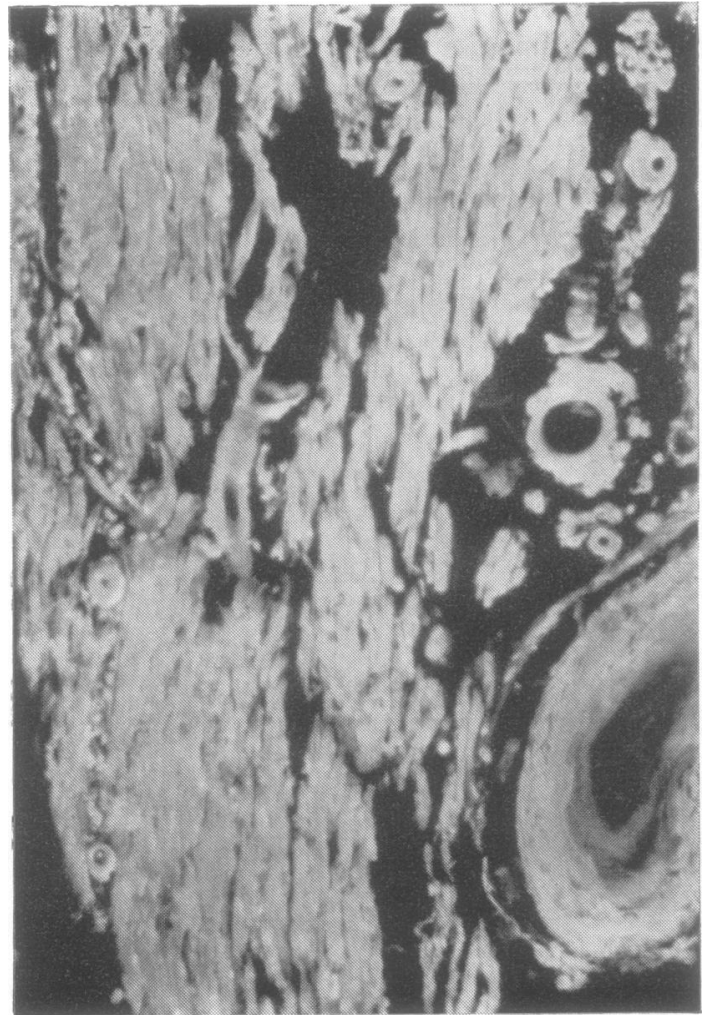

FIG. 4 Case 1. Trigeminal root: infiltration along the course of nerve fibres and in walls of blood vessels. Thioflavin $T$ (Mercury vapour lamp, exciter filter Schott UG1, barrier filter Schott -50$), \times 200$.

meninal ganglion were remarkably well preserved and only a few cells showed evidence of degeneration in the form of loss of nuclei and poor cytoplasmic staining. Proliferation of capsule cells was seen in a few places, but there were no nodules of Nageotte or other evidence of neuronal loss. The nerve fibres within the ganglion showed some degenerative changes in the form of irregular beading, or clubshaped, spherical, or ovoid retraction bulbs. A few argyrophilic baskets were present around neuronal cell bodies. The peripheral branches of the trigeminal nerves were not available for examination, but fibre bundles emerging from the ganglion contained abundant well myelinated axons.

MOTOR ROOT OF TRIGEMINAL NERVE Medial to the entry of the sensory root into the pons there were skeins of well-myelinated large axons forming irregularly convoluted whorls, resembling those seen

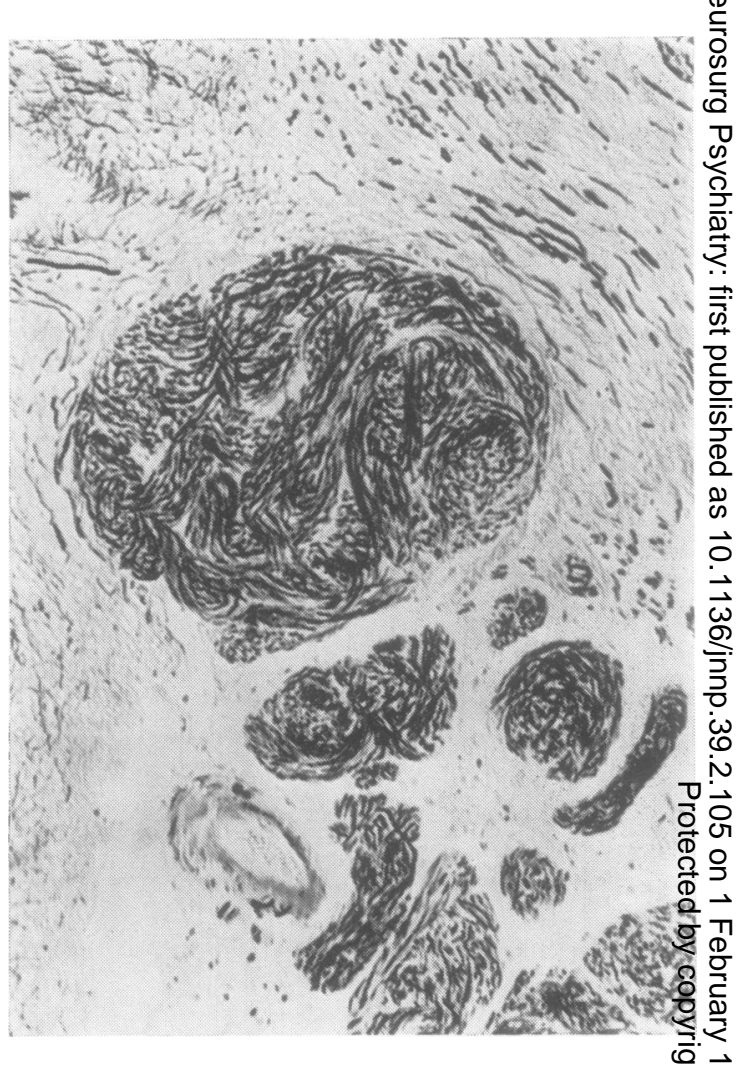

FIG. 5 Case 1. Trigeminal root: tangled whorls of large calibre nerve fibres, probably derived from motor. root. Glees-Marsland silver impregnation, $\times 120$.

in traumatic neuromas of the nerve roots (Fig. 5). $\stackrel{\unrhd}{\stackrel{D}{\circ}}$ Their origin could not be traced with certainty, but their position and calibre of axons suggested that they were derived from the motor root.

CENTRAL TRIGEMINAL PATHWAYS The intrapontine course of the sensory trigeminal fibres showed totalo loss of axons and myelin sheaths. No obvious 3 lesions were seen in the motor, principal sensory, and mesencephalic nuclei of the 5th nerve. On the othero hand, the spinal trigeminal tract showed severe degeneration and its nucleus marked, but not total,, loss of neurones. In addition, the blood vessels within the tract and the nucleus were thickened and their walls infiltrated with an abnormal homogeneous material showing the staining reactions of substance B (Fig. 6). This infiltration, of variable thickness, 0 appeared to be predominantly adventitial and didw not encroach upon the lumen of the vessels. 


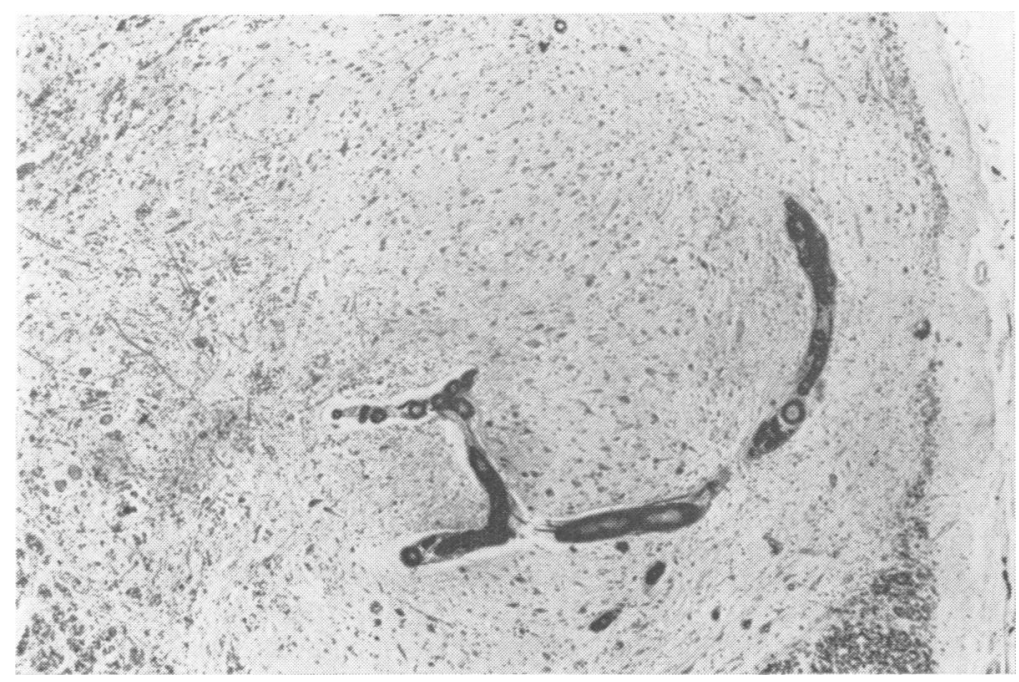

FIG. 6 Case 1. Nucleus of spinal tract of trigeminal nerve: total loss of myelinated fibres in tract and infiltration of walls of blood vessels. Luxol fast blue-cresyl violet, $\times 60$.

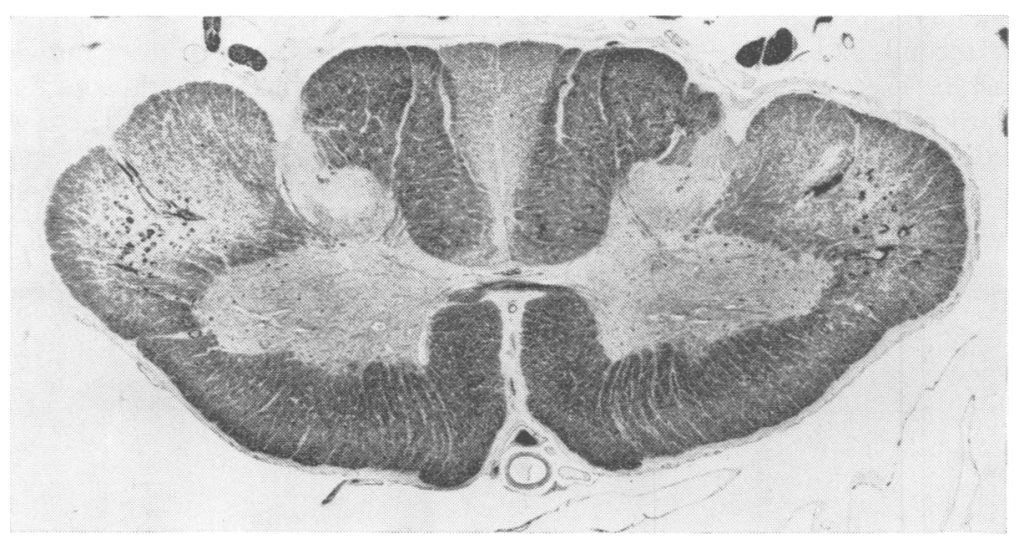

FIG. 7 Case 1. Cervical cord: degeneration of crossed pyramidal tracts and of fasciculus gracilis; infiltration of blood vessels in lateral columns only. Luxol fast blue-cresyl violet,$\times 10$.

SPINAL CORD Throughout the spinal cord there was almost total loss of myelinated fibres in the crossed pyramidal tracts, the uncrossed tracts being unaffected (Fig. 7). On tracing the lesions into the medullary pyramids, the fibre loss became less conspicuous and at pontine level no abnormality could be detected in the corticospinal tracts. Throughout the degenerate lateral columns the blood vessels showed conspicuous changes similar to those described above. The thickening and infiltration appeared to be mainly adventitial, but some vessels showed medial thickening with subintimal infiltration and possibly some narrowing of the lumen. The infiltrating material was almost exclusively substance $B$, but tiny fragments of substance A were found in some vessels. These vascular changes extended into the medullary pyramids, but not above that level.

The posterior columns showed rarefaction, but not total loss, of fibres in the lumbar segments. This loss became more severe at higher levels, and in the cervical segments was almost total in the fasciculus gracilis, the fasciculus cuneatus being well preserved. By contrast with the pyramidal tracts, abnormal vessels were almost completely absent in the degenerated parts of the posterior columns.

DORSAL ROOT GANGLIA A few random posterior root ganglia available for examination showed no significant lesions.

MENINGEAL VESSELS A few vessels in the ventral cleft 
of the spinal cord showed infiltration with substance B. The vessels over the surface of the cord showed no abnormality. A few circumferential vessels of the brain stem showed traces of substance B in their walls. The blood vessels over and in the cerebral hemispheres showed no abnormality.

\section{CASE 2}

A married woman, aged 38 years, with one child was first seen in 1968. No significant previous illnesses were recorded. Onset of left-sided trigeminal neuralgia occurred in September 1967. There were no trigger phenomena; inter-paroxysmal facial aching caused insomnia. Carbamazepine was ineffective. The skin on the affected side of the face was drier than on the right. In January 1968 the facial pains began to subside but they were replaced by numbness and paraesthesiae. There was no other neurological involvement. By February 1968 there was impairment of taste on the left side; tongue, gums, and cheek on the left side all felt numb. Examination confirmed impairment of touch, pain, and temperature in the distribution of the second and third divisions of the left trigeminal nerve. There was no motor trigeminal impairment. Corneal reflexes were retained. Investigations revealed no evidence of syphilis, sarcoidosis, systemic lupus, or scleroderma.
Neuroradiological studies (pneumoencephalography and vertebral angiography) were normal. Blood and क spinal fluid were normal. Serum proteins and electro-ça phoresis were normal and the ESR was $15 \mathrm{~mm} / 1 \mathrm{~h}$.

In December 1968 she began to notice a numbness

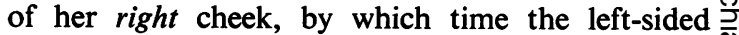
numbness had spread to involve the forehead and eye. The corneal reflex was absent on the left and there was a left-sided Horner syndrome (Fig. 8a). On that side, the sensory loss was now dense and she developed a neuropathic keratitis which required tarsorraphy. On the right side, during the following year, the numbness spread over the whole face. In June 1969 further investigations were normal except for a raised sedimentation rate $(48 \mathrm{~mm} / 1 \mathrm{~h})$. By early os 1970 she had lost $9 \mathrm{~kg}(20 \mathrm{lb})$ in weight since the $\vec{O}$ beginning of her illness. She found chewing and swallowing difficult and would lose the food in her ${ }_{\sigma}$ mouth. A right tarsorraphy was necessary. When her eyes were closed she could scarcely appreciate passive movements of the tip of the nose or of her upper lip. Taste was absent except for a fleeting i sensation during the act of swallowing. There wa now probable weakness of the masticatory muscle o ESR was $56 \mathrm{~mm} / 1 \mathrm{~h}$; DAT 1 in 256. Prednisone $5 \mathrm{mg}$ 은 thrice daily was begun in February 1970. There was no change during 1970 but in January 1971 ear erosion of the left ala nasi was detected (Fig. 8b), and

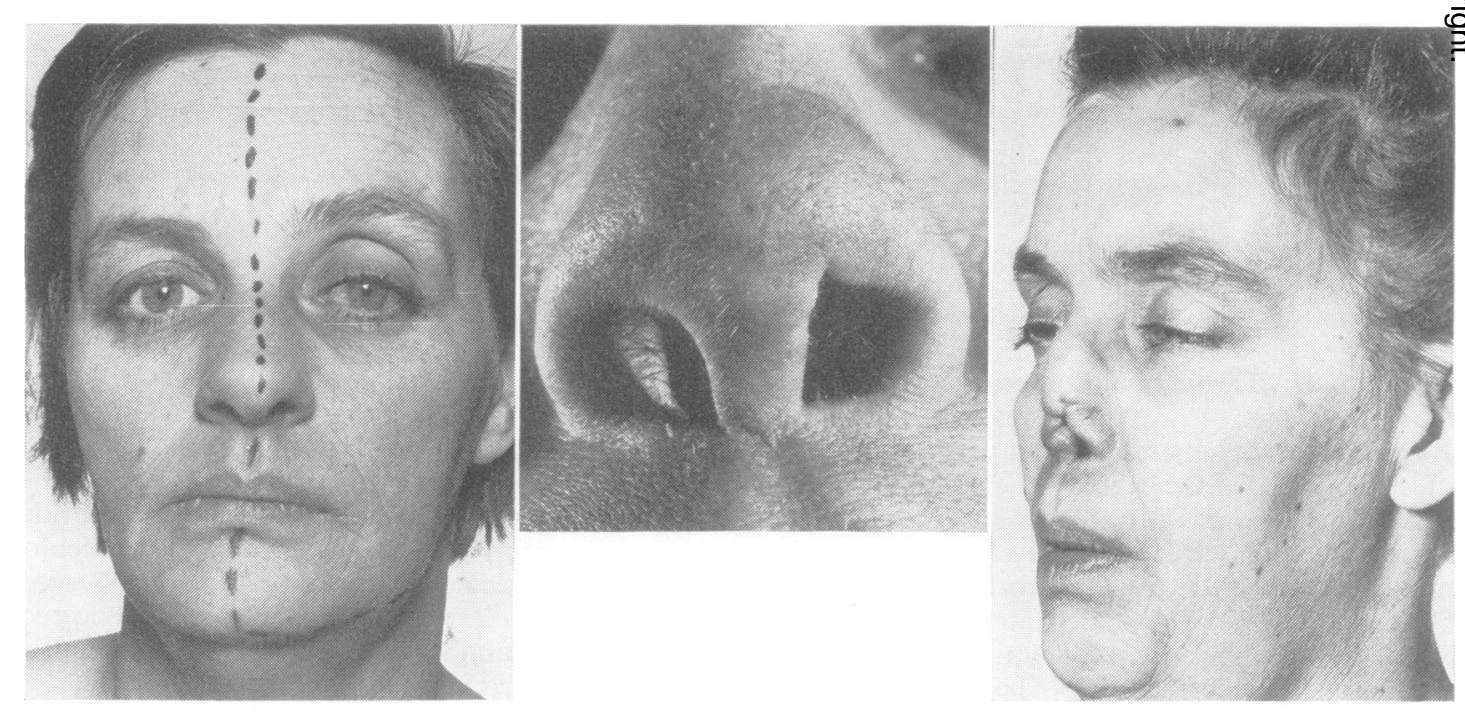

(a) (b) (c)

FIG. 8 Case 2. (a) Fifteen months after onset; left Horner syndrome, left trigeminal sensory loss, absent left corneal reflex, early neuropathic keratitis, early sensory loss on right cheek. (b) Two years later; early erosion of left ala nasi. Bilateral trigeminal anaesthesia with bilateral neuropathic keratitis. (c) One year later; erosion of nasal septum and collapse of nose. 
during the course of that year the whole of the nasal septum disintegrated and her nose collapsed (Fig. $8 c)$. No leprosy bacilli were discovered in her nose and nasal biopsy showed no evidence of granuloma. During the years 1972 and 1973 there was no new development. Her general condition was poor, her weight remained at about $50 \mathrm{~kg}(110 \mathrm{lb})$ and she was depressed. The soft tissues of the nose shrank but did not disappear as in case 1 . She was provided with a nasal prosthesis and she continued her work as a domestic help. Sedimentation rates were recorded during these years at 34 and $52 \mathrm{~mm} / 1 \mathrm{~h}$ respectively. Serum proteins and electrophoresis remained normal; negative antinuclear factor; positive rheumatoid screening test, DAT 1 in 4.

Early in 1974, while in her bath, she discovered a patch of numbness on the outer side of the left leg below the knee. It has persisted unchanged until the present (June 1975) and measured about $5 \mathrm{~cm}$ by $3.8 \mathrm{~cm}$ ( 2 in. by $1 \frac{1}{2}$ in.) and appears to be in the area supplied by the musculocutaneous nerve. There is no alteration of the skin and no thickening of nerves. Electrodiagnostic tests were normal. The sensory loss involves all modalities but it is not complete. Her general health has improved, she has put on $5.4 \mathrm{~kg}$ in weight and is less depressed. She is taking prednisone $5 \mathrm{mg}$ daily. Her nervous system is otherwise normal. In recent months there have been several episodes of postural vertigo which have subsided; menstruation has been irregular. There has been no sign of returning trigeminal sensibility. There is virtual bilateral total superficial anaesthesia; vibration cannot be appreciated on the malar or mandibular prominences; passive movements of the tip of the nose and upper lips remain only feebly appreciated.

So in this case, also, we have a presentation of a lesion in both trigenimal sensory systems, erosion of the nose, but so far the only indication of a lesion elsewhere in the nervous system consists of a patch of numbness on one leg.

\section{DISCUSSION}

Both cases presented with trigeminal sensory loss which, in the first case, was bilateral from the outset, and in the second case became bilateral after 15 months. Trophic erosion of the nose took place in each case. The trigeminal sensory loss was not dissociated; all superficial modalities were involved from the outset; deep pressure and vibration became affected later. Taste was lost. Signs of involvement of the trigeminal motor system also eventually occurred. No other cranial nerve was involved in either case. A spinal cord lesion developed in the first case after some 15 years. In the second case, the only other sign to appear, after eight years, is a patch of numbness on the left leg. No evidence of systemic disease was found in either case. The first patient died 21 years after the beginning of her illness. The second patient remains at work as a domestic help.

In the literature of trigeminal neuropathy there are several references to its occurrence in association with connective tissue disease (Beighton et al., 1968; Kaltreider and Talal, 1969; Gumpel, 1970a, b; Ashworth and Tait, 1971; Lundberg and Werner, 1972; Whaley et al., 1973). In the majority of these cases the presentation of illness was not with the trigeminal lesion; the latter usually appeared during the course of the systemic disorder. Lundberg and Werner suggested that the neuropathy is caused by vascular lesions in the medulla because of the sparing of the corneal reflexes and the occasional bilateral nature of the disorder of the trigeminal sensory system. Barraquer-Bordas et al. (1973) question this interpretation of the signs in bilateral cases. The relationship of unilateral trigeminal sensory neuropathy to Bell's palsy appears to be a tenuous one (Seward, 1962; Ch'ien and Halsey, 1970; Eggleston and Haskell, 1972).

Shafar and Copp (1970) have described a case in which unilateral trigeminal sensory neuropathy was the only manifestation of widespread peripheral neuropathy for a period of 10 years. It is obvious that nerve conduction studies may reveal involvement of limb nerves when the only clinical feature remains numbness of the face.

None of these associations was found in our first patient on postmortem examination. The lesions consisted of degeneration of the trigeminal root and its central pathways, and of the pyramidal tracts and posterior columns in the spinal cord. This was associated with deposition of an amyloid-like substance. The degeneration of the affected tracts was not accompanied by significant lesions in their cells of origin, suggesting a 'dying-back' mechanism. The association of trigeminal lesions with long tract degenerations is unusual and we are not aware of a similar combination reported either in genetic or sporadic system degenerations.

The infiltrating substance was confined to 
connective tissue structures and involved the walls of the blood vessels in the affected tracts in the central nervous system. In the trigeminal root, it was apparently deposited on the endoneurium surrounding the degenerated fibres as well as on blood vessels, the infiltration stopping abruptly at the glio-Schwannian junction. The substance consisted of two components, differing in their staining properties, one sparse and found predominantly at the glio-Schwannian junction (substance $A$ ), the other abundant and widely distributed (substance B). According to the criteria laid down by Wolman (1971) for identification of amyloid-like substances, material showing all the specific staining reactions is 'amyloid', that showing only some of them is 'pseudoamyloid'. By these criteria, our substance A represents true amyloid, substance B pseudoamyloid. Regrettably, no material containing substance $\mathrm{A}$ was available for electron microscopy. Its fibrillary structure can only be inferred from its optical properties such as birefringence and dichroism. The ultrastructure of substance B was homogeneous and would therefore be designated by some authorities as 'hyaline', a term reserved by Wolman for material showing none of the staining reactions of amyloid. The relationship between amyloid and pseudoamyloid, or amyloid and hyaline, remains obscure. It is, however, of interest that Coimbra and Andrade (1971a) observed deposition of hyaline as well as fibrillary amyloid in early cases of the Portuguese variant of familial amyloid neuropathy and suggested that the hyaline material might be a precursor of true amyloid.

The distribution of amyloid-like substances in our case was unusual and has no counterpart in any known type of amyloidosis. It bears no resemblance to any form of amyloid neuropathy, familial or sporadic (reviewed by Henson and Urich, 1970 and by Urich, 1976). Two unusual cases deserve a brief mention, that of Daly et al. (1957) and of Borghi and Tagliabue (1961). In both these cases, amyloid deposits were found in Gasserian ganglia removed surgically for the treatment of trigeminal neuralgia. At the time of operation these patients showed no evidence of systemic amyloidosis or peripheral neuropathy, and their trigeminal symptoms were unilateral. In the absence of follow-up studies the noso- logical position of this localized Gasserian amyloidosis remains uncertain. It is also of interest that hyaline bodies, mainly related to blood vessels, were found in the dorsal root ganglia in cases of hereditary sensory radicular neuropathy studied by Denny-Brown (1951) and by van Bogaert (1953), but not in other similar cases. The material on Denny-Brown's case stained with Congo red.

In the central nervous system amyloid deposition is common in the 'congophilic angiopathy' in the cerebral cortex of old people, sometimes associated with senile dementia of the Alzheimer type (Corsellis and Brierley, 1954). In his extensive studies on senile amyloidosis of the cardiovascular system, Schwartz (1969) emphasized this involvement of cortical vessels, but did not mention similar changes in any other part of the central nervous system.

The strict association of the vascular amyloidosis or pseudoamyloidosis with tract degenerations in our case suggests a causa of relationship between the two processes. It could be argued that the vascular lesions were the $-\vec{T}$ primary event, and the tract degenerations $\frac{\mathbb{D}}{0}$ represented a summation effect of multiplể ischaemic lesions leading to Wallerian degeneras. tion. This problem has its counterpart i peripheral amyloid neuropathy, which, in oे Kernohan and Woltman's (1942) view, represented an ischaemic neuropathy due to obliteration of the vasa nervorum. Doubts on this interpretation were cast when Dyck and Lambert (1969) demonstrated a selective loss of unmyelinated axons and when Coimbra and $\overline{\bar{o}}$ Andrade (1971b) suggested that fibre degeneration preceded the deposition of amyloid. Similarly, Schwartz's view that amyloidosis was the cause of senile dementia was refuted by Wiśniewski and Terry (1973). In our case, it would appear unlikely that a primary vascular disease should be confined to well-defined tracts. There was no evidence that the patency of the vessels was significantly impaired and there were no 0 focal areas of ischaemic necrosis. We therefore prefer to interpret the findings as a primary system degeneration and the deposition of amyloid-like substances as an epiphenomenon.

It remains to be explained why these vascular $N$ changes are not seen more frequently in system $\omega$ degenerations. It is well known that amyloid 
deposition may be due to generalized disturbances, such as excess of circulating light chain immunoglobulins, or to strictly local causes, such as observed in certain types of tumours. In addition, it may be suggested that in some cases the interplay of local and general factors may be responsible both for the deposition and for the localisation of amyloid. To quote Schwartz (1969) '. . . amyloid is precipitated when a morbid factor circulating in the blood, lymph, or cerebrospinal liquor, joins a compound located in diseased structural elements of tissues and cells'. Perhaps the lesions in our case represent an example of senile amyloidosis localized in degenerating nervous tissue.

There is at present no indication that the condition of our second patient is due to a similar combination or distribution of lesions. So, while trigeminal neuropathy with progressive nasal ulceration forms a distinct clinical syndrome, it would be premature to suggest that it constitutes a nosological entity.

We are indebted to Dr N. G. Sanerkin for his necropsy findings and for referring the material for further examination.

\section{REFERENCES}

Ashworth, B., and Tait, G. B. W. (1971). Trigeminal neuropathy in connective tissue disease. Neurology (Minneap.), 21, 609-614.

Barraquer-Bordas, L., Torrent, R., Codina, M., and Solans, T. (1973). Neuropathie sensitive du trijumeau, pure, bilaterale, avec troubles trophiques oculaires. Revue Neurologique, 129, 222-226.

Beighton, P. H., Gumpel, J. M., and Cornes, N. G. M. (1968). Prodromal trigeminal sensory neuropathy in progressive systemic sclerosis. Annals of Rheumatic Diseases, 27, 367-369.

Bogaert, L. van (1953). Étude histopathologique d'une observation d' arthropathie mutilante symétrique familiale. Sa non-appartenance à la syringomyélie. Ses rapports avec la neuropathie radiculaire sensorielle héréditaire (Hicks et Denny-Brown). Acta Neurologica et Psychiatrica Belgica, 53, 37-54.

Borghi, G., and Tagliabue, G. (1961). Primary amyloidosis in the Gasserian ganglion. Acta Neurologica et Psychiatrica Scandinavica, 37, 105-110.

Ch'ien, L. T., and Halsey, J. H. (1970). Trigeminal sensory neuropathy and Bell's palsy. New England Journal of Medicine, 282, 224-225.

Coimbra, A., and Andrade, C. (1971a). Familial amyloid polyneuropathy: an electron miscroscope study of the peripheral nerve in five cases. 1. Interstitial changes. Brain, 94, 199-206.

Coimbra, A., and Andrade, C. (1971b). Familial amyloid polyneuropathy: an electron microscope study of the peripheral nerve in five cases. 2 . Nerve fibre changes. Brain, 94, 207-212.

Corsellis, J. A. N., and Brierley, J. B. (1954). An unusual type of presenile dementia (atypical Alzheimer's disease with amyloid vascular change). Brain, 77, 571-587.

Daly, D. D., Love, J. G., and Dockerty, M. B. (1957). Amyloid tumour of Gasserian ganglion. Journal of Neurosurgery, 14, 347-352.

Denny-Brown, D. (1951). Hereditary sensory radicular neuropathy. Journal of Neurology, Neurosurgery, and Psychiatry, 14, 237-252.

Dyck, P. J., and Lambert, E. H. (1969). Dissociated sensation in amyloidosis. Archives of Neurology (Chic.), 20, 490-507.

Eggleston, D. J., and Haskell, R. (1972). Idiopathic trigeminal sensory neuropathy. Practitioner, 208, 649-655.

Gumpel, J. M. (1970a). Isolated trigeminal neuropathy. Lancet, 1, 310.

Gumpel, J. M. (1970b). Trigeminal sensory neuropathy in connective tissue disease. New England Journal of Medicine, 282, 514.

Henson, R. A., and Urich, H. (1970). Metabolic neuropathies. In Handbook of Clinical Neurology, vol. 8, pp. 1-28. Edited by P. J. Vinken and G. W. Bruyn. North Holland: Amsterdam.

Kaltreider, H. B., and Talal, N. (1969). The neuropathy of Sjögren's syndrome; trigeminal nerve involvement. Annals of Internal Medicine, 70, 751-762.

Kernohan, J. W., and Woltman, H. W. (1942). Amyloid neuritis. Archives of Neurology and Psychiatry, 47, 132-140.

Lundberg, P. O., and Werner, I. (1972). Trigeminal sensory neuropathy in systemic lupus erythematosus. Acta Neurologica Scandinavica, 48, 330-340.

Schwartz, P. (1969). Cardiovascular amyloidosis in the aged. Geriatrics, 24/8, 81-97.

Seward, M. H. E. (1962). Anaesthesia of the lower lip. A problem in differential diagnosis. British Dental Journal, $113,423-426$.

Shafar, J., and Copp, E. P. (1970). Isolated trigeminal neuropathy. Lancet, 1, 242-243.

Spillane, J. D., and Wells, C. E. C. (1959). Isolated trigeminal neuropathy: a report of 16 cases. Brain, 82, 391-416.

Urich, H. (1976). Diseases of peripheral nerves. In Greenfield's Neuropathology, 3rd edn. Edited by W. Blackwood and J. A. N. Corsellis. Arnold: London. (In press.)

Whaley, K., Webb, J., McAvoy, B. A., Hughes, G. R. V., Lee, P., MacSween, R. N. M., and Buchanan, W. W. (1973). Sjögren's syndrome; clinical associations and immunological phenomena. Quarterly Journal of Medicine, 42, 513-548.

Wiśniewski, H. M., and Terry, R. D. (1973). Morphology of the aging brain, human and animal. Progress in Brain Research, 40, 167-186.

Wolman, M. (1971). Amyloid, its nature and molecular structure. Comparison of a new toluidine blue polarized light method with traditional procedures. Laboratory Investigation, 25, 104-110. 